\title{
Localization of DIR1 at the tissue, cellular and subcellular levels during Systemic Acquired Resistance in Arabidopsis using DIR1:GUS and DIR1:EGFP reporters
}

Marc J Champigny ${ }^{1,4}$, Heather Shearer ${ }^{1,4}$, Asif Mohammad ${ }^{1}$, Karen Haines ${ }^{1}$, Melody Neumann², Roger Thilmony ${ }^{3,5}$, Sheng Yang $\mathrm{He}^{3}$, Pierre Fobert ${ }^{4}$, Nancy Dengler ${ }^{2}$ and Robin $\mathrm{K}$ Cameron ${ }^{1 *}$

\begin{abstract}
Background: Systemic Acquired Resistance (SAR) is an induced resistance response to pathogens, characterized by the translocation of a long-distance signal from induced leaves to distant tissues to prime them for increased resistance to future infection. DEFECTIVE in INDUCED RESISTANCE 1 (DIR1) has been hypothesized to chaperone a small signaling molecule to distant tissues during SAR in Arabidopsis.

Results: DIR1 promoter:DIR1-GUS/dir1-1 lines were constructed to examine DIR1 expression. DIR1 is expressed in seedlings, flowers and ubiquitously in untreated or mock-inoculated mature leaf cells, including phloem sieve elements and companion cells. Inoculation of leaves with SAR-inducing avirulent or virulent Pseudomonas syringae pv tomato (Pst) resulted in Type III Secretion System-dependent suppression of DIR1 expression in leaf cells. Transient expression of fluorescent fusion proteins in tobacco and intercellular washing fluid experiments indicated that DIR1's ER signal sequence targets it for secretion to the cell wall. However, DIR1 expressed without a signal sequence rescued the dir1-1 SAR defect, suggesting that a cytosolic pool of DIR1 is important for the SAR response.
\end{abstract}

Conclusions: Although expression of DIR1 decreases during SAR induction, the protein localizes to all living cell types of the vasculature, including companion cells and sieve elements, and therefore DIR1 is well situated to participate in long-distance signaling during SAR.

\section{Background}

Acquired resistance, or "immunization" of plants was originally documented more than seventy years ago in a review published by Kenneth Chester in which varying degrees of immunity were observed in plants that had recovered from an initial pathogen attack [1]. The term systemic acquired resistance (SAR) was originally used by Ross to describe systemic resistance induced by necrosis-causing viruses in tobacco [2] and is more generally defined as a defense mechanism induced by a localized infection that results in broad-spectrum

\footnotetext{
* Correspondence: rcamero@mcmaster.ca

'Department of Biology, McMaster University, Hamilton, ON L8S 4K1 Canada Full list of author information is available at the end of the article
}

resistance in distant tissues to normally virulent pathogens $[3,4]$.

Research using tobacco, cucumber and, more recently, Arabidopsis models indicates that SAR occurs in distinct stages. The first, or induction, stage is initiated when a necrosis-causing pathogen infects a leaf and results in either the formation of a localized hypersensitive response (HR) and local resistance, or in diseaseinduced necrosis [3]. A recent report demonstrated systemic immunity in the absence of necrotic cell death in the induced leaf [5], highlighting the fact that the precise cellular mechanisms governing the initiation of SAR are still unclear. Formation of the necrotic lesion results in a 10 to 50 -fold accumulation above basal levels of the plant defense hormone, salicylic acid (SA),[6-11] and in
C Biomed Central

(c) 2011 Champigny et al; licensee BioMed Central Ltd. This is an Open Access article distributed under the terms of the Creative Commons Attribution License (http://creativecommons.org/licenses/by/2.0), which permits unrestricted use, distribution, and reproduction in any medium, provided the original work is properly cited. 
the expression of pathogenesis-related $(P R)$ genes $[6,11,12]$

During the initiation stage of SAR, a mobile signal or signals is induced to travel and is later perceived in distant, uninfected tissues. Several lines of evidence indicate that the signal travels through the phloem, including girdling experiments in tobacco that reduce the translocation of molecules through phloem tissue. Additionally, the pattern of sucrose transport from source to sink leaves in Arabidopsis was similar to transport of the SAR signal from induced leaves to protect upper leaves against Pseudomonas syringae pv maculicola (Psm). Although these and other experiments [reviewed in 13] suggest the SAR signal is phloem-mobile, cell-to-cell movement down the petiole, or a combination of these two modes of transport cannot be ruled out.

The discovery that SA levels in the phloem rise dramatically in SAR-induced tobacco [9] and cucumber [10] led to the hypothesis that SA itself may be a SAR mobile signal [14]. SA was shown to be critically involved in the SAR pathway because transgenic tobacco plants expressing a salicylate hydroxylase gene $(N a h G)$ were unable to accumulate SA or to manifest a SAR response [14]. However, a number of experiments provide evidence that $\mathrm{SA}$ is not a SAR mobile signal. Cucumber plants in which induced leaves were detached prior to the accumulation of SA in their petioles still manifested a SAR response in systemic tissue [15]. Furthermore, grafting experiments utilizing transgenic $N a h G$ tobacco demonstrated that NahG-expressing rootstocks blocked in the accumulation of SA were nonetheless competent to translocate a mobile signal to the scion [16].

The establishment phase of SAR involves the perception of the mobile signal(s) in distant tissue, resulting in a modest accumulation of SA and expression of $P R$ genes in Arabidopsis and tobacco [7,8,11]. In the final, or manifestation, stage of SAR, the plant responds to normally virulent pathogens in a resistant manner [3]. Manifestation of SAR is associated with the expression and activity of a set of SAR genes [17] including the previously described $P R$ genes. An earlier, more rapid or more abundant accumulation of these SAR proteins may be the molecular basis for systemic resistance. The physiological function of many of these genes has not been determined but increases in peroxidase activity in induced cucumber [18], chitinase activity in Arabidopsis and cucumber [19], as well as antifungal properties in vitro [20] suggest that these proteins play a role in producing a resistant state.

Isolation and characterization of Arabidopsis mutants has been a powerful approach to decipher the mechanism of SAR. By screening a collection of T-DNA tagged
Arabidopsis lines for mutants that fail to develop SAR following induction with avirulent Pseudomonas syringae pv tomato (Pst), the defective in induced resistance 1-1 (dir1-1) mutant was identified [21]. The dir1-1 mutant was not compromised in basal resistance and, interestingly, overexpression of DIR1 did not enhance disease resistance or lead to a constitutive SAR response. Petiole exudates, enriched for phloem sap, collected from SARinduced wild-type leaves were effective in inducing the SAR marker gene $P R-1$ when infiltrated into wild-type or dir1-1 plants, suggesting that the long-distance SAR signal was present in these wild type petiole exudates and that dir1-1 can perceive this signal. However, exudates similarly collected from dir1-1 leaves were incapable of inducing PR-1 expression in wild-type leaves, suggesting that this mutant is defective either in the synthesis of the SAR mobile signal or its transport to distant leaves [21]. These data and the fact that DIR1 encodes a putative lipid transfer protein led to the hypothesis that DIR1 is involved in long distance signaling and may chaperone a lipid signal to distant leaves during SAR $[21,13]$.

Lipid transfer proteins (LTPs) are ubiquitous in plants and are associated with many developmental and stress response processes [22]. The structure of a number of LTPs has been determined revealing that they possess a consensus motif of eight cysteine residues engaged in four disulphide bridges forming a central hydrophobic cavity which can bind long chain fatty acids [22]. Lascombe et al. [23] determined the structure and lipid binding properties of DIR1 expressed in the yeast Pichia pastoris using fluorescence and X-ray diffraction. DIR1 shares some structural and lipid binding properties with the LTP2 family. In vitro, DIR1 can bind two monoacylated phospholipids and contains two proline-rich $\mathrm{SH} 3$ domains. SH3 domains participate in protein-protein interactions in numerous proteins [23]. Lascombe et al. postulate that the DIR1 SH3 domains may play a role in interacting with the putative SAR signal receptor in distant leaves. A number of studies implicate glycerolipids [24,25], methyl salicylate (MeSA) and azelaic acid (AA) as SAR long distance signal candidates [26-28]. Overexpression/SAR studies in dir1-1 identified two tobacco DIR1 orthologs indicating that DIR1 is important for SAR in both Arabidopsis and tobacco [29]. A recent paper by Chanda et al. [30] provides evidence suggesting that glycerol-3-phosphate (G3P) may also be a SAR long distance signal.

If DIR1 is chaperoning a signal(s) to distant leaves during SAR, we hypothesize that DIR1 accesses sieve elements for long distance movement. Therefore, DIR1 promoter transgenic lines were investigated to localize DIR1 in leaves at the cellular and subcellular levels in healthy untreated plants and during SAR. Our results 
indicate that the DIR1 promoter directs constitutive expression in seedlings and all leaf cell types. Moreover, although DIR1 expression is reduced upon SAR induction, DIR1 is still expressed in all living cell types comprising the vascular tissue.

\section{Results}

\section{Localization of DIR1 in leaves during SAR}

Previous RNA and protein gel blot expression studies indicated that DIR1 is expressed constitutively at low levels in rosette leaves of 3 to 4 week old plants and its expression is reduced after SAR induction [21]. If DIR1 is involved in the long distance signaling stage of the SAR pathway, it is possible that DIR1 is expressed in the phloem, specifically companion cells, providing it direct access to the phloem for long distance movement. Moreover, expression limited to the phloem would be consistent with low DIR1 RNA and protein levels observed in whole leaves [21]. DIR1 expression in leaves was examined using the $ß$-glucuronidase (GUS) reporter gene. The GUS reporter was chosen to amplify the weak DIR1 expression signal and allow visualization of DIR1 expression in various tissues and at the cellular level. Transgenic plant lines were created in which the DIR1 promoter region was placed upstream of GUS in wildtype (ecotype Ws) plants or upstream of a DIR1-GUS fusion in the dir1-1 mutant background (see Methods for details). A number of plant lines were examined at four weeks post germination (wpg) for GUS activity before and during SAR. DIR1pro:GUS in Ws lines 1, 11, 23 and DIR1pro:DIR1-GUS in dir1-1 lines 3, 15, 29 were mock-inoculated ( $10 \mathrm{mM} \mathrm{MgCl} 2)$, inoculated with SAR-inducing avirulent Pst (avrRpt2) or left untreated. Similar results were observed in all plant lines (Figure 1 and Additional Files 1,2) Inoculated leaves and uninoculated systemic leaves from the same plant were collected at 14 or 20 hours post inoculation (hpi), stained for GUS activity and observed using light microscopy. Under low magnification, abundant GUS activity was observed in untreated and mock-inoculated leaves in the vasculature and mesophyll cells in both the DIR1pro: GUS-11 and DIR1pro:DIR1-GUS-29 lines. In contrast, less intense GUS staining was observed in inoculated and systemic leaves of both transgenic lines $(11,29)$ inoculated with avirulent Pst (Figure 1A). Due to differences in cell density and vacuole size of cells in the midvein, secondary vein and mesophyll, it is not possible to compare GUS activity levels between these tissues. Therefore GUS activity was measured separately in each of these tissues using a relative scale of 0 to 4 , where 0 represents little to no GUS activity and 4 represents intense GUS activity or staining (Figure 1B, C) to quantify the observed reduction in GUS activity observed in Figure 1A. Intense staining occurred in the midvein and secondary veins in mock-inoculated or untreated leaves of both the DIR1pro:GUS-11 and DIR1pro:DIR1-GUS29 lines, whereas the level of GUS activity was reduced in inoculated and uninoculated systemic leaves of plants inoculated with SAR-inducing Pst (avrRpt2). A similar reduction in GUS activity was observed in mesophyll cells of inoculated or systemic leaves collected from plants induced for SAR compared to untreated or mock-inoculated leaves (Figure 1). Comparable results for DIR1pro:GUS-23 in Ws and DIR1pro:DIR1-GUS-3 in dir1-1 are presented as Additional Files 1,2 and 3.

These studies indicate that the DIR1 promoter region initiates expression of GUS and DIR1-GUS throughout the leaf and confirms previous RNA gel blot data [21] that DIR1 expression is reduced after SAR induction with Pst (avrRpt2). DIR1 expression in the vasculature was examined in more detail to determine if DIR1 is expressed in phloem cells using both DIR1pro:DIR1GUS-29/dir1-1 and DIR1pro:GUS-11/Ws lines. GUSstained leaf and petiole midveins from 4 week-old plants were embedded, sectioned and viewed under high magnification. GUS activity was present in all living cell types including the developing xylem tracheary elements, xylem parenchyma, phloem and phloem parenchyma in midveins of untreated, mock-inoculated, inoculated and systemic leaves from plants induced for SAR (Figure 2). DIR1 expression was reduced, but still detectable in all cell types of the midvein in leaves induced for SAR, including both companion cells and sieve elements of the phloem (Figure 2 and Additional File 4). DIR1-GUS activity was also observed in all cells of untreated petiole midveins (see Additional file 5HI). Therefore, DIR1 is expressed in the phloem before and during SAR induction and may access the phloem for long distance movement during SAR.

Expression of DIR1 in seedlings, roots and flowers was also examined using the DIR1pro-DIR1-GUS-29/dir1-1 line. DIR1-GUS activity was observed throughout sevenday old seedlings including the roots, trichomes and in flowers and flower bolts of mature plants (see Additional file $5 \mathrm{~A}-\mathrm{G}$ ).

\section{Reduction in DIR1 expression during SAR induction is Pst- dependent}

A number of studies have demonstrated that virulence effectors delivered by the Type III Secretion System (T3SS) of Pst are involved in suppressing Arabidopsis cell wall-mediated basal resistance which includes the formation of cell wall callose appositions near Pst colonies and the expression of a number of secreted proteins including some LTPs [31-33]. We hypothesized that the reduction in DIR1 expression after inoculation with Pst observed in this and our previous study [21] could be the result of T3SS delivery of virulence effectors into 
A
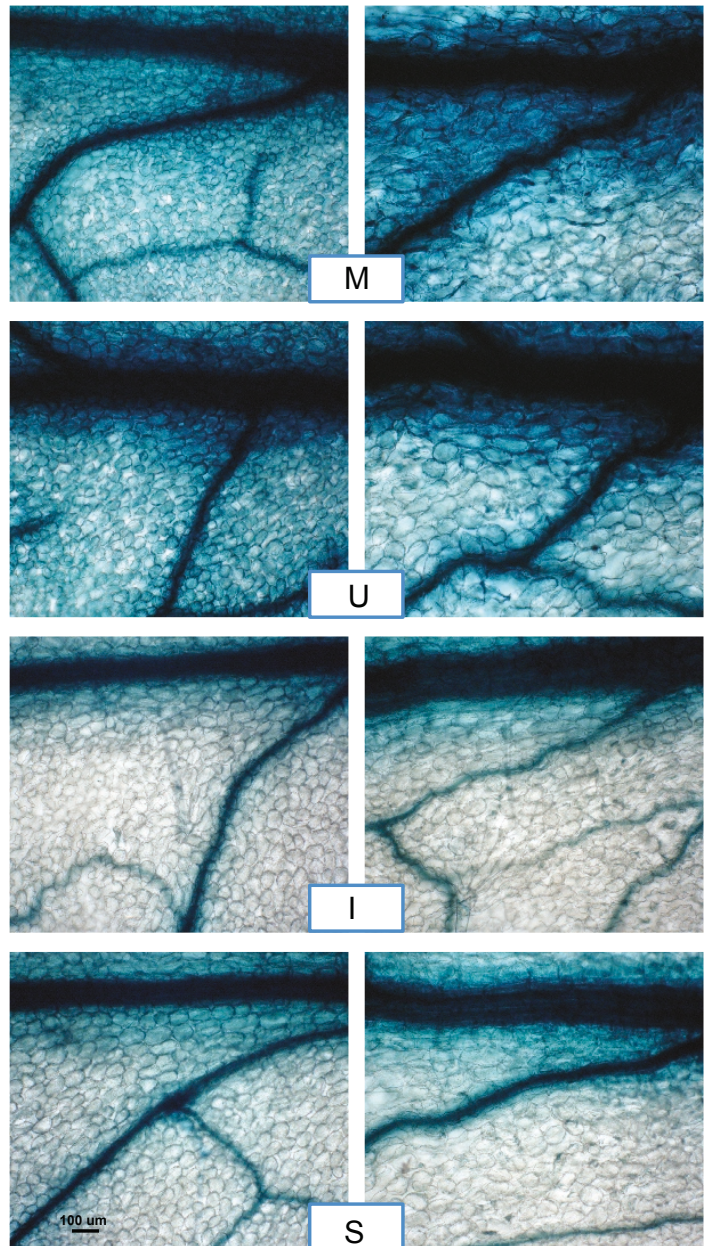

DIR1pro:DIR1GUS-29/dir1-1
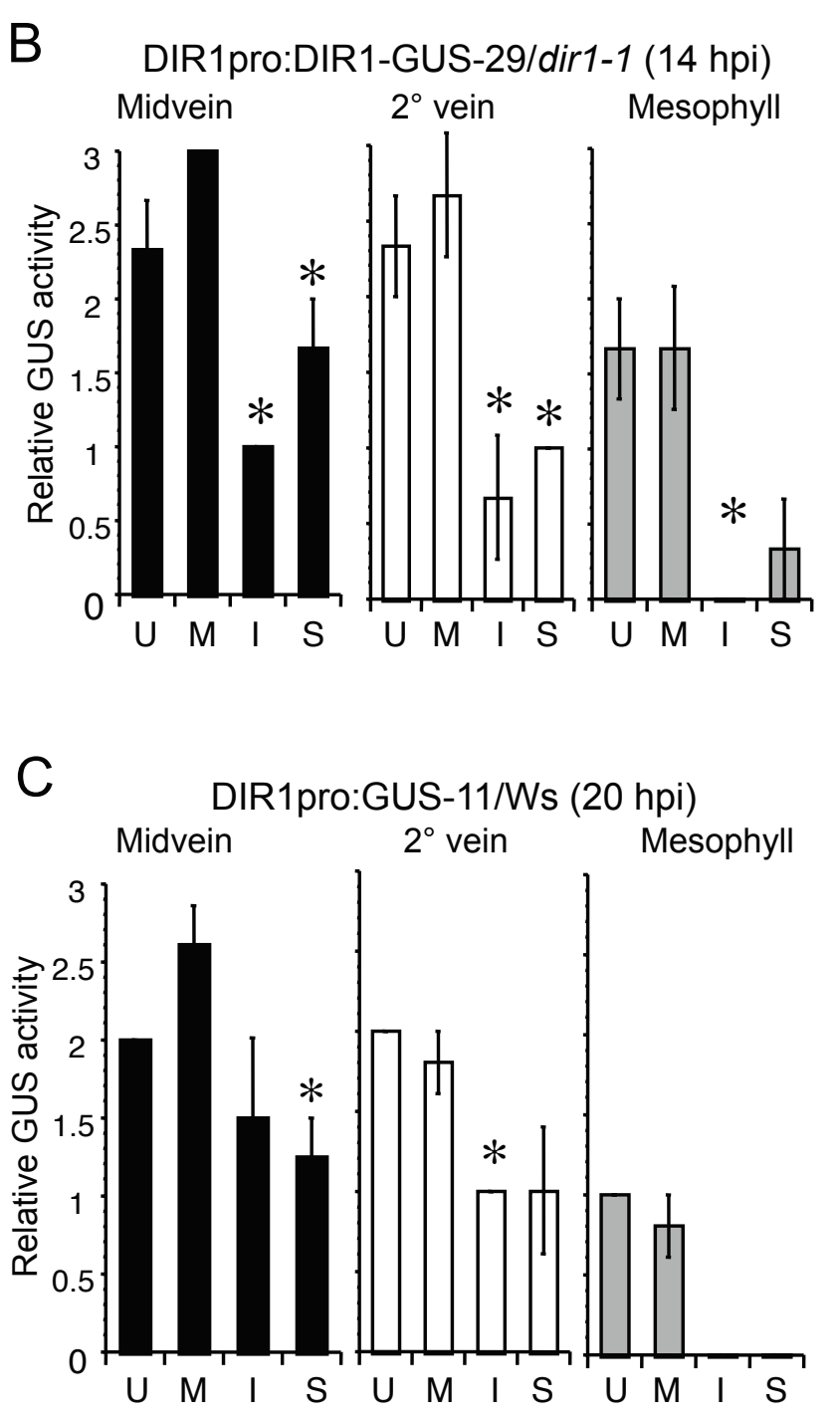

Figure 1 DIR1 expression in leaves using the DIR1 promoter:GUS plant lines. (A) DIR1pro:DIR1-GUS-29/dir1-1 and DIR1pro:GUS-11/WS plants lines (3.5 wpg) were left untreated $(U)$, mock-inoculated (M) or inoculated with $10^{6} \mathrm{cfu} \mathrm{ml}^{-1}$ of SAR-inducing PstavrRpt2 (I) and harvested at $14 \mathrm{hpi}, 20,40 \mathrm{hpi}$ and subjected to histochemical GUS analysis. Staining pattern were similar at all time points, therefore $14 \mathrm{hpi}$ is shown for DIRpro:DIR1-GUS-29/dir1-1 and 20 hpi leaves for DIRpro:GUS-11/Ws. Systemic leaves were also collected from plants that were SAR induced (S). Representative leaves from each line were photographed in a single sitting without adjusting microscope settings and two different leaves are shown. The bar represents $100 \mu \mathrm{m}$. Measurement of relative GUS activity in (B) DIR1pro:DIR1-GUS-29/dir7-1 and (C) DIR1pro:GUS/Ws. Leaves from the experiment presented in panel A were scored using a subjective relative scale of 0 to 4 , with 0 representing little GUS staining and 4 representing intense GUS staining. $U$ = uninoculated, $M=$ mock-inoculated, I = inoculated leaf from SAR-induced plants, $S=$ systemic leaf from SAR-induced plants. The asterisk $\left(^{*}\right)$ denotes a significant difference (student's $t$ test) between mock-inoculated leaves and leaves induced for SAR. This experiment was repeated once with similar results.

the plant cell. To test this hypothesis, DIR1 expression was monitored in wild-type plants inoculated with either virulent Pst or a hrpS Pst mutant. A high inoculum dose was used $\left(10^{8} \mathrm{cfu} \mathrm{ml}^{-1}\right)$ because nonpathogenic Pst hrp mutants do not reliably induce host transcriptional responses at the lower doses [34] typically used in Arabidopsis-Pst inoculation experiments. Leaves were collected at 3,6,9 and 18 hpi for RNA gel blot analysis. The
T3SS is not functional in hrpS mutants and therefore no Pst-encoded virulence effectors would be delivered into the plant cell $[35,36]$. DIR1 was expressed at low levels in untreated leaves and its expression increased from 3 to $18 \mathrm{hpi}$ after infection with hrpS Pst (Figure 3A). In leaves inoculated with wild-type virulent Pst, DIR1 expression was reduced at 6 and $9 \mathrm{hpi}$, but this suppression was attenuated by $18 \mathrm{hpi}$ (Figure 3A). These data 


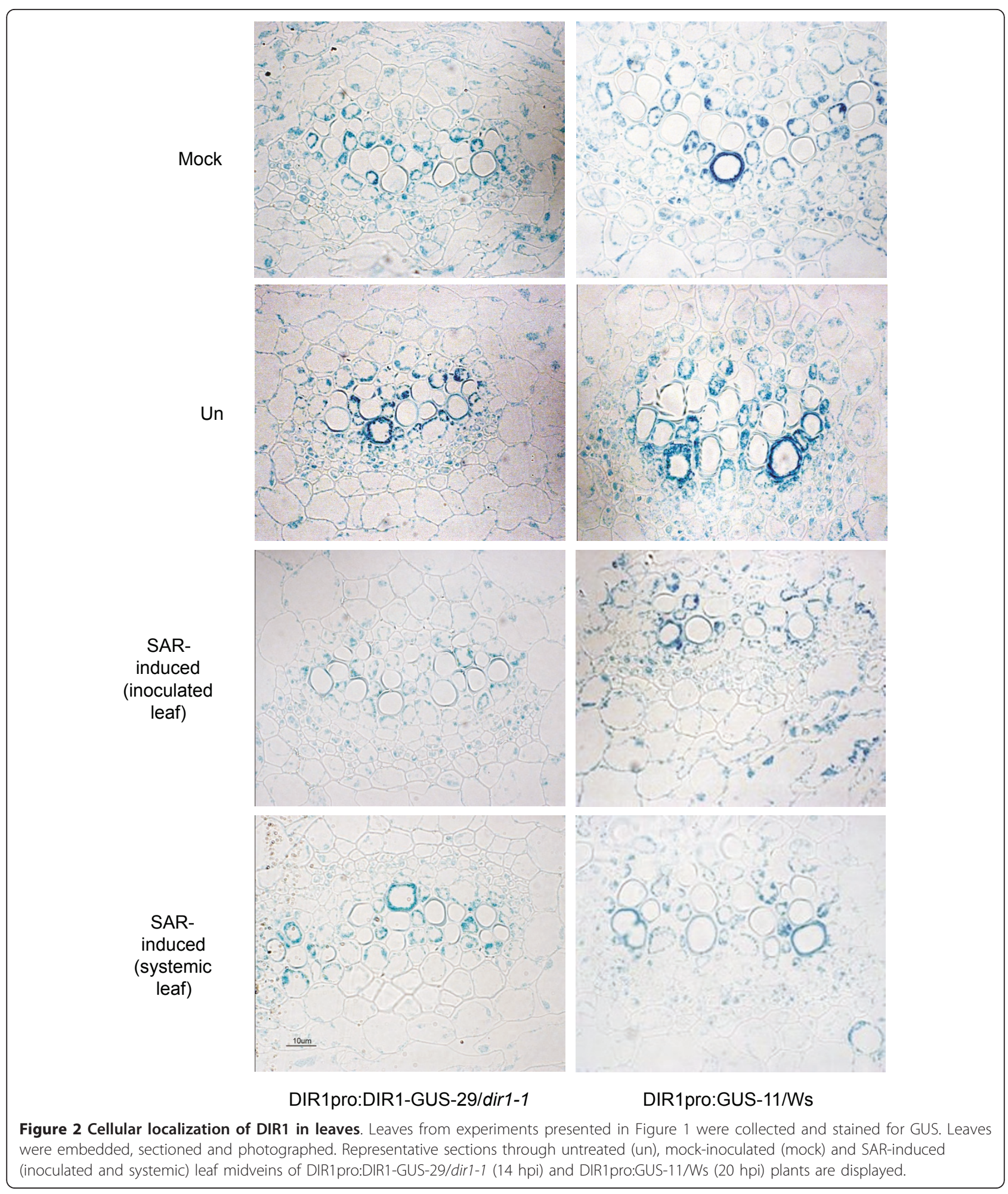

demonstrate that reduction in DIR1 observed after inoculation with Pst is not a response by the plant, but rather a consequence of the delivery of Pst virulence effectors into the plant cell.
To examine which cell types are affected by Pst virulence effectors, DIR1-GUS expression in the DIR1pro: DIR1-GUS-29/dir1-1 line was monitored after inoculation with wild type Pst and a hrpA Pst mutant that does 


\section{A}

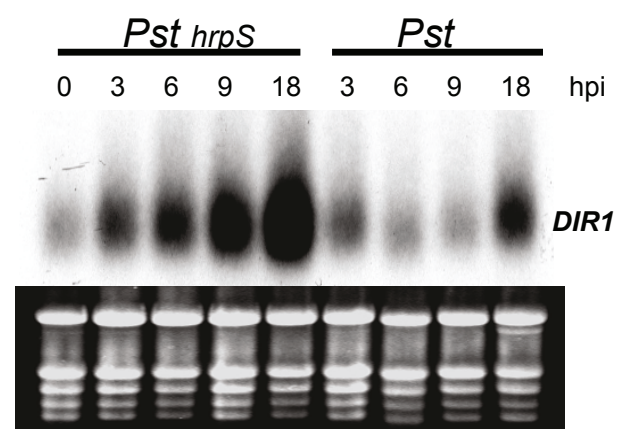

B
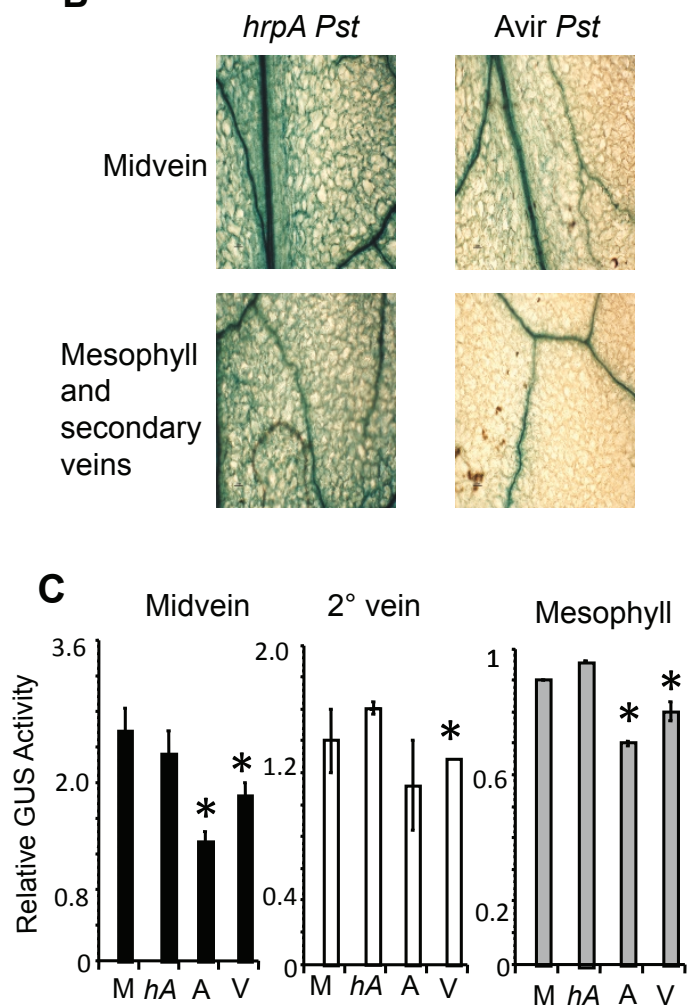

Figure 3 Reduction in DIR1 expression during SAR is Pstdependent. (A) Plants were vacuum-infiltrated with $10^{8} \mathrm{cfu} \mathrm{ml}^{-1}$ hrpS Pst or Pst, followed by RNA gel blot analysis of DIR1 expression at 0,3,6,9 and 18 hpi. Total RNA before blotting is shown to indicate equal RNA loading per well. This experiment was repeated once with similar results. (B, C) DIR1 pro:DIR1-GUS-29/dir1-1 plants were inoculated with $10^{6} \mathrm{cfu} \mathrm{ml}^{-1}$ PstavrRpt2 (Avir) or hrpA Pst. Inoculated leaves were collected at $12 \mathrm{hpi}$ and photographed (B) and relative GUS activity was determined in midveins, secondary veins and mesophyll cells using the 0-4 subjective GUS scale. The asterisk (*) denotes a significant difference (student's T- test) between mockinoculated $(M)$ and leaves inoculated with hrpA $(h A)$ or avirulent (A) or virulent $(V)$ Pst (C). This experiment was repeated once with similar results. not make the major pilus protein, HrpA and therefore cannot form the T3SS Hrp pilus or deliver effectors into the plant cell [36]. The hrpA mutant or wild-type virulent or avirulent Pst (avrRpt2) were inoculated $\left(10^{6} \mathrm{cfu}\right.$ $\mathrm{ml}^{-1}$ dose) into DIR1pro:DIR1-GUS-29/dir1-1. Inoculated leaves were collected at 6 and $12 \mathrm{hpi}$, stained and scored for GUS activity. Similar results were obtained at both 6 and $12 \mathrm{hpi}$, therefore just the $12 \mathrm{hpi}$ data is presented in Figure 3B and 3C. Mock-inoculated leaves and leaves from plants inoculated with hrpA Pst displayed high GUS activity in the midvein, secondary vein and mesophyll cells compared to leaves inoculated with virulent (data not shown) or avirulent Pst (Figure 3B). These visual results were corroborated by determining the relative GUS activity using the subjective GUS scale as described above. GUS activity was reduced in the midvein, secondary vein and mesophyll cells in leaves inoculated with either avirulent or virulent Pst as compared to leaves inoculated with hrpA Pst (Figure 3C). Therefore inoculation with virulent or avirulent Pst leads to suppression of DIR1 expression in the midvein, secondary vein and mesophyll cells of leaves in a T3SS-dependent manner.

\section{DIR1 is targeted to the cell wall}

Lipid transfer proteins enter the endoplasmic reticulum (ER) and secretory pathway as preproteins under the direction of a short, N-terminal ER entry peptide of 20 to 26 amino acids that is cleaved after entry into the ER. The mature proteins are secreted outside the cell and are typically associated with cell walls [37-39], although several of these proteins have been discovered intracellularly within protein storage vacuoles or glyoxisomes $[40,41]$. The functionality of the predicted DIR1 signal sequence was examined by Agrobacterium-mediated transient transformation with T-DNA encoding fulllength DIR1 fused to the EYFP (enhanced yellow fluorescent protein) reporter (35S:DIR1-EYFP), truncated DIR1 lacking the putative signal sequence fused to EYFP (35S:DIR1 ${ }^{41-25}$-EYFP) or 35S:EYFP into Nicotiana tobaccum followed by laser scanning confocal microscopy to localize EYFP fusion proteins in tobacco leaf epidermal cells.

Localization of DIR $1^{\Delta 1-25}$-EYFP was identical to that of the EYFP control, such that fluorescence was observed in 60 of 60 cells at the cell periphery, in cytoplasmic strands and also within the nucleus (Figure 4A, B). Detection of these proteins in the nucleus was likely due to passive diffusion from the cytosol. The $27 \mathrm{kDa}$ EYFP protein, as well as the DIR $1^{\Delta 1-25}$-EYFP fusion are smaller than the $60 \mathrm{kDa}$ exclusion limit of nuclear pores [42] such that nuclear detection of cytosolic fluorescent fusion proteins is commonly observed in plant cells [43]. DIR1-EYFP exhibited two distinct patterns of 


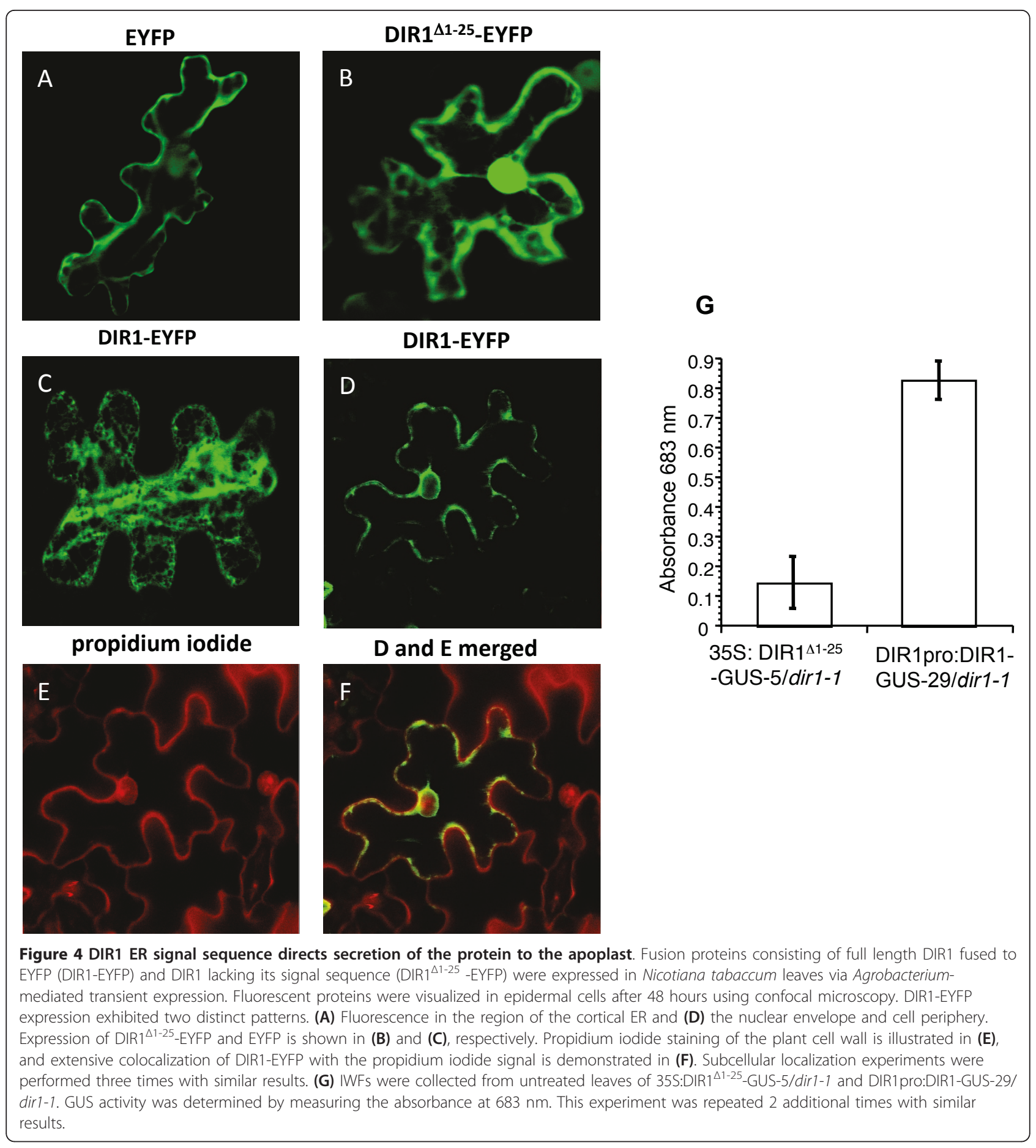

localization. In a small number of cells (5/60), DIR1EYFP was detected in a discrete network particularly enriched near the plasma membrane (Figure 4C) coincident with the cortical ER. In a majority of cells, (55/60), DIR1-EYFP was localized to the nuclear and cell periphery (Figure 4D). Tobacco epidermal cells have a large central vacuole largely restricting the cytoplasm to a thin layer near cell boundaries, making it difficult to distinguish between plasma membrane and cell wall localization. To confirm that DIR1-EYFP was secreted to the cell wall, cells were counterstained with propidium iodide, a dye which accumulates in the apoplast as it is excluded by intact plasma membranes $[44,45]$. DIR1EYFP partially colocalized (Figure 4F) with the 
propidium iodide signal (Figure 4E), demonstrating that the signal sequence directed secretion of DIR1-EYFP out of tobacco epidermal cells into the cell wall. Patches of DIR1-EYFP signal did not colocalize with propidium iodide, but rather with regions surrounding the nucleus and the cell periphery indicating that some DIR1 molecules localize to the ER secretory system and perhaps the cytosol.

Transgenic lines that express DIR1 lacking its signal sequence in the dir1-1 mutant (35S:DIR1 $1^{\Delta 1-25}$-GUS in dir1-1) were constructed and used to demonstrate the functionality of the DIR1 signal sequence in Arabidopsis. A number of lines were characterized (see Methods) and line 5 was chosen for further study. GUS activity in the leaves of 35Spro: DIR1 ${ }^{\Delta 1-25}$-GUS-5/dir1-1 line was monitored by inoculating leaves with $10^{6} \mathrm{cfu} \mathrm{ml}^{-1}$ Pst (avrRpt2) followed by GUS staining at $14 \mathrm{hpi}$. Similar to DIR1 promoter-directed expression (Figures 1 and 2), GUS activity in the 35Spro: DIR1 ${ }^{\Delta 1-25}$-GUS-5/dir1-1 line was higher in untreated and mock-inoculated leaves compared to leaves inoculated with avirulent Pst (Figure 5A,B and Additional File 6). DIR $1^{\Delta 1-25}$-GUS was expressed in all cell types of the leaves similar to DIR1 promoter-driven expression of DIR1-GUS. These data indicate that expression from the $35 \mathrm{~S}$ promoter, like that from the DIR1 promoter region, is reduced in response to inoculation with Pst. However, unlike DIR1 promoter-directed expression, 35S promoter-directed expression of DIR $1^{\Delta 1-25}$-GUS in the midvein and secondary vein of systemic leaves of inoculated plants was similar to untreated or mock-inoculated leaves (Figure 5A, B and Additional File 6). Other researchers have also observed a reduction in $35 \mathrm{~S}$ promoter-driven expression after pathogen inoculation. For example, expression of GUS in 35S:GUS transgenic pear was significantly reduced following infection with Erwinia amylovora [46] and in Arabidopsis and tobacco roots following infection with Heterodera and Globodera nematodes [47].

To demonstrate that the DIR1 signal sequence does target DIR1 to the cell wall in Arabidopsis, intercellular washing fluids (IWFs) were collected from DIR1pro: DIR1-GUS-29/dir1-1 and 35S:DIR1 ${ }^{\Delta 1-25}$-GUS-5/dir1-1 untreated leaves from 4 week old plants. IWFs consist of cell wall associated proteins and molecules and provide information about the soluble molecules associated with plant cell walls $[48,49]$. IWFs collected from DIR1pro:DIR1-GUS-29/dir1-1 and 35S:DIR1 ${ }^{\Delta 1-25}$-GUS-5/ dir1-1 leaves were assayed for GUS activity (see Methods). IWFs from DIR $1^{\Delta 1-25}$-GUS plants displayed low GUS activity while IWFs from DIR1-GUS plants displayed high GUS activity (Figure 4G). Therefore when

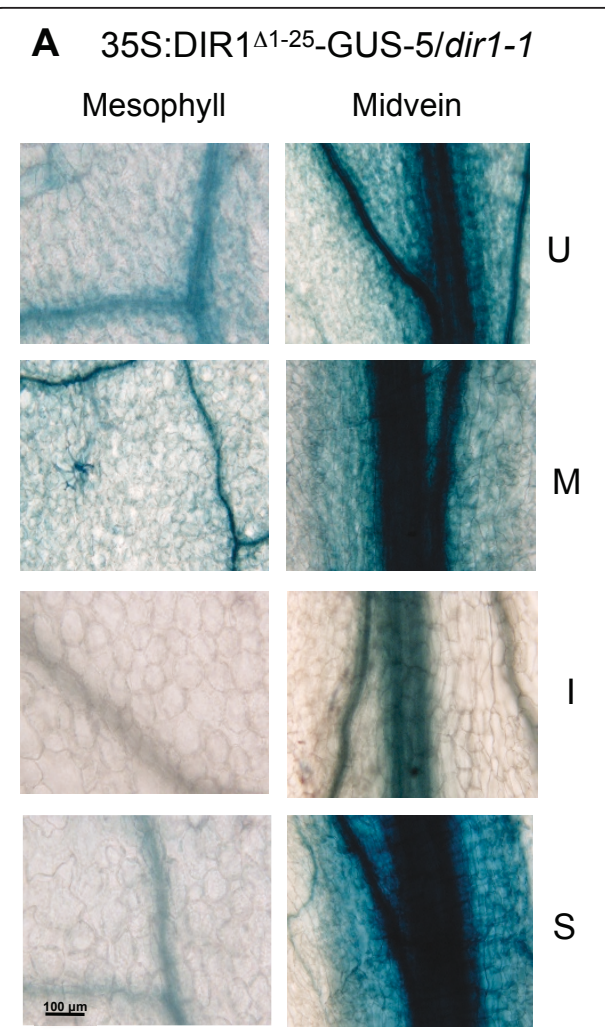

B

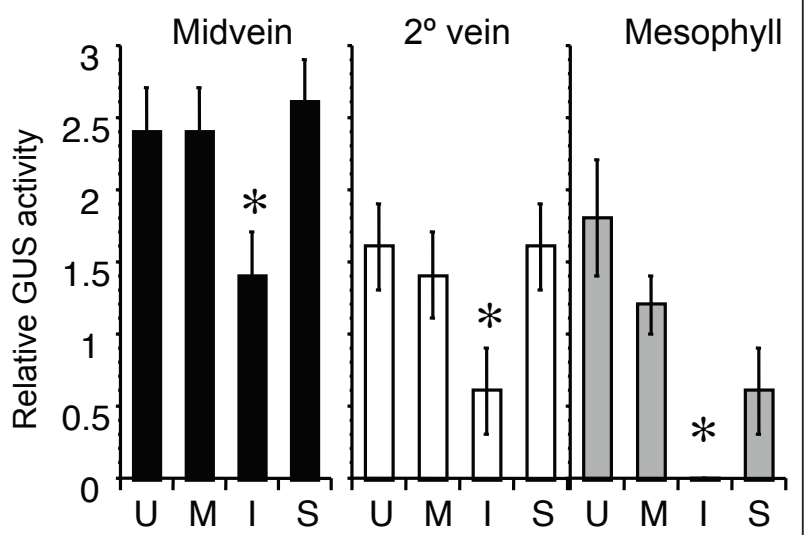

Figure $\mathbf{5}$ Localization of DIR1 lacking its signal sequence. 35S: DIR1 ${ }^{\Delta 1-25}$-GUS-5/dir1-1 plants were left untreated (U), mockinoculated (M) or induced for SAR with PstavrRpt2 $\left(10^{6} \mathrm{cfu} \mathrm{ml}^{-1}\right)$. Inoculated (I) and systemic leaves (S) were collected from inoculated plants at $14 \mathrm{hpi}$. Leaves were stained for GUS activity and photographed in (A) or GUS activity levels were determined in the midveins, secondary veins and mesophyll cells of untreated $(U)$, mock-inoculated (M) or leaves induced for SAR (I and S) in (B). The asterisk $\left(^{*}\right)$ denotes a significant difference (student's $t$ test) between untreated and inoculated leaves from SAR-induced plants (I). This experiment was repeated once with similar results. 
DIR1 possesses its native signal sequence, DIR1-GUS activity is detected in IWFs which are enriched for soluble cell wall proteins. However, little GUS activity was detected when the native DIR1 signal sequence was removed. These results corroborate the tobacco immunofluorescence analysis demonstrating that the native DIR1 signal sequence targets DIR1 to the cell wall in Arabidopsis.

\section{Expression of DIR1-GUS or DIR1 $1^{\Delta 1-25}$-GUS rescues the SAR} defect in dir1-1

We hypothesize that DIR1 may be involved in long distance signaling during SAR and travel cytoplasmically via the phloem and/or cell to cell. Evidence to date indicates that proteins destined to travel in the phloem in Arabidopsis are made in companion cells and enter sieve elements via companion cell-sieve element plasmodesmata [50-52]. However, DIR1 is targeted to the cell wall via the secretory system and according to current cell biology knowledge, DIR1 would have no access to the cytosol and plasmodesmata. We hypothesize that DIR1's targeting signal sequence is cleaved or becomes nonfunctional upon SAR induction allowing it to remain in the cytosol with access to plasmodesmata. If this was true, then DIR1 without its signal sequence may still function during SAR. To test this hypothesis, SAR assays were performed with DIR1pro:DIR1-GUS29/dir1-1 and 35S:DIR1 ${ }^{\Delta 1-25}$-GUS-5/dir1-1 lines plus Ws and dir1-1. Plants were either induced for SAR with $10^{6} \mathrm{cfu} \mathrm{ml}^{-1}$ Pst (avrRpt2) or mock-inoculated on two lower leaves, followed by challenge inoculation with $10^{5} \mathrm{cfu} \mathrm{ml}^{-1}$ virulent Pst in distant leaves two day later. Bacterial densities were monitored in challenged leaves at 3 dpi. Wild-type Ws plants were SAR-competent as demonstrated by the 10 -fold reduction in Pst levels in plants induced for SAR versus those that were mock-inoculated, while the dir1-1 mutant displayed high levels of Pst in plants that were or were not induced for SAR (Figure 6A). Both transgenic lines expressing either DIR1-GUS or DIR $1^{\Delta 1-25}$-GUS were SAR competent as demonstrated by the 6-fold and 4fold decrease, respectively, in Pst levels in induced versus mock-inoculated plants (Figure 6A). A replicate experiment is shown in Figure $6 \mathrm{~B}$ in which the transgenic lines displayed a 7 - to 8 -fold SAR response compared to 5 -fold in Ws. Results similar to Figures 6A and $6 \mathrm{~B}$ were observed using additional transgenic lines (DIR1pro;DIR1-GUS/dir1-1 lines 3, 15 and 35S: DIR1 ${ }^{\Delta 1-25}$-GUS/dir1-1 lines 17,20$)$ providing evidence that expression of DIR1-GUS or DIR1 $1^{\Delta 1-25}$-GUS restores the SAR defect in the dir1-1 mutant. More importantly, these data suggest that removal of the DIR1 signal sequence has no deleterious effect on DIR1's ability to participate in SAR.
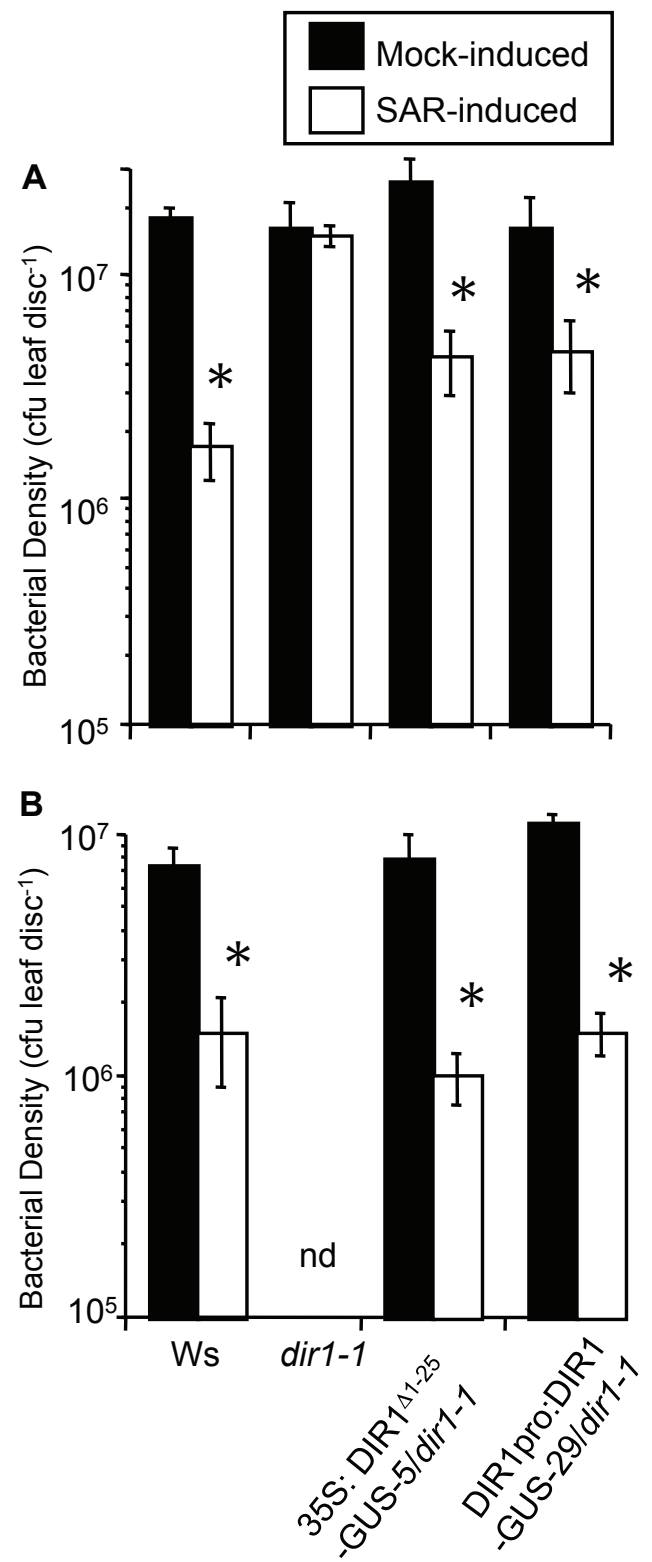

Figure 6 Expression of DIR1-GUS or DIR1 ${ }^{\Delta 1-25}$-GUS rescues the SAR defect in dir1-1. SAR assays were conducted on Ws, dir 1-1, DIR1 pro:DIR1-GUS-29/dir1-1 and 35S: DIR1 ${ }^{\Delta 1-25}$-GUS-5/dir1-1 by inoculating with $10 \mathrm{mM} \mathrm{MgCl}$ (mock-induced) or inducing for SAR with Pst-avrRpt2 (SAR-induced) in 1 to 2 lower leaves, followed by challenge inoculation with virulent Pst in distant leaves 2 days later. Bacterial density determination was performed in challenged leaves 3 dpi. Asterisks $(*)$ denote a significant difference (student's t-test) in bacterial densities between challenged distant leaves of mock- and SAR-induced plants. Representative results are presented in (A) and (B) and these experiments have been repeated numerous times with similar results (see text for details). nd = not determined.

\section{Discussion}

The non-specific lipid transfer proteins (LTPs) comprise a large, multigene family present in numerous plant species [39]. LTPs are basic polypeptides of approximately 
7-9 kD, whose key structural feature is the LTP fold formed by four disulphide bridges between eight conserved cysteine residues [22]. The LTP fold forms a tunnel-like cavity and in vitro studies indicate it accommodates various lipids, including phospholipids, fatty acids, glycolipids, prostaglandin and jasmonic acid [53-58]. Due to their ability to bind lipids in vitro, LTPs were originally hypothesized to traffick lipids between intracellular membranes [59]. However, this function seems unlikely as a number of LTPs have been demonstrated to be synthesized as preproteins containing an ER signal sequence such that the mature proteins are secreted to the apoplast [37].

Although the biochemical mechanisms involved are not clear, LTP proteins play important roles in plant defense against pathogens. Several LTPs exhibit antimicrobial activity in vitro $[60,61]$ and overexpression of select LTP or LTP-like proteins leads to enhanced local resistance against bacterial and fungal pathogens in Arabidopsis and tobacco [62,63]. DIR1 is the first LTP protein whose function in pathogen resistance is defined genetically, as the dir1-1 Arabidopsis mutant is impaired in systemic resistance to Pst (SAR) but local resistance responses remain intact. Furthermore, $35 \mathrm{~S}$ promotermediated overexpression of DIR1 does not lead to enhanced basal resistance or a more robust SAR response [21], strongly suggesting that DIR1 does not participate directly in defense against Pst, but instead plays a role in systemic disease signaling.

The overall goal of this study was to investigate the signaling role of DIR1 during SAR by localizing it at the tissue, cellular and subcellular levels. A number of transgenic lines were created in which the DIR1 promoter region was placed upstream of GUS or a DIR1GUS fusion in Ws and dir1-1, respectively. Examination of these lines indicated that the DIR1 promoter region initiated expression of GUS and DIR1:GUS in seedlings, roots and floral tissues and in all living cells including the veins and mesophyll cells of untreated and mock-inoculated leaves. This was somewhat unexpected as we had hypothesized that DIR1 expression might be limited to the vasculature which would explain the constitutive, but low levels of DIR1 expression observed in leaves [21], while still providing DIR1 access to the phloem for movement during SAR. During SAR induction, DIR1-GUS expression was reduced in mesophyll cells and vascular tissue of inoculated and distant systemic leaves of plants induced with SAR-inducing Pst (avrRpt2). RNA gel-blots [21] revealed that DIR1 transcript levels declined following SAR induction in leaves. Therefore reduced GUS activity observed in SAR-induced DIR1pro:GUS transgenic plants is the result of decreased transcription driven by the DIR1 promoter region.
Reduction in DIR1 expression could be part of the SAR response or could be due to Pst-derived effector molecules delivered into plant cells. To test this hypothesis, expression of DIR1 in leaves inoculated with SARinducing avirulent Pst, virulent Pst, or with a Pst hrpS mutant, was determined using RNA gel blot analysis. DIR1 expression was reduced in leaves inoculated with virulent Pst at 6 and 9 hpi, however by $18 \mathrm{hpi}$, DIR1 expression was no longer suppressed. Reduction in DIR1 expression was not observed in leaves inoculated with Pst hrpS. Instead, DIR1 transcripts accumulated abundantly at 3, 6, 9 and 18 hpi. A high inoculum dose was used $\left(10^{8} \mathrm{cfu} \mathrm{ml}^{-1}\right)$ because nonpathogenic Pst hrp mutants do not reliably induce host transcriptional responses at the lower doses [34] typically used in Arabidopsis-Pst inoculation experiments. Similar experiments with the DIR1pro:GUS or DIR1pro:DIR1-GUS plant lines using a lower inoculum level $\left(10^{6} \mathrm{cfu} \mathrm{ml}^{-1}\right)$ demonstrated that Pst Hrp-dependent suppression of DIR1 expression occurs in the midvein, secondary veins and mesophyll cells at 14 and 20 hpi. Numerous in planta bacterial growth studies have demonstrated that the infection process proceeds faster in high compared to low dose experiments [64-68]. Therefore, we speculate that the difference in timing of suppression of DIR1 expression in these two experiments is due to the high versus low inoculum doses used.

Collectively, these data suggest that suppression of DIR1 expression occurs through the action of effector molecules delivered through the Pst T3SS. This supports numerous studies in which genes associated with Arabidopsis cell wall defense, including a number of LTPs, are suppressed in a Pst Hrp-dependent manner [31-33]. Transcriptional mechanisms are involved in the Pstmediated downregulation of DIR1 expression in DIR1pro:DIR1-GUS and 35S:DIR1 ${ }^{\Delta 1-25}$-GUS-5 lines, but it is also possible that post-transcriptional mechanisms or DIR1-GUS instability contribute to the observed expression patterns.

Hrp-dependent suppression of DIR1 occurs in all cell types within inoculated leaves and in distant uninoculated leaves. Recently it was discovered that Pseudomonas syringae suppresses plant defenses not only in the infected leaf but also in systemic tissues, rendering the plant more susceptible to subsequent infection, a phenomenon known as Systemic Induced Susceptibility (SIS) [64]. SIS observed after Pseudomonas infection of Arabidopsis requires the bacterial toxin coronatine $[69,70]$, a structural and functional mimic of the defense hormone jasmonic acid [71]. Interestingly, Pst hrp mutants are deficient in the production of coronatine [70]. Reduction of DIR1 expression in systemic tissue may therefore involve the action of widely mobile, bacterially produced molecules such as coronatine. 
DIR1 expression in the vasculature was examined in more detail to determine if DIR1 has access to the phloem and therefore the potential for movement to distant leaves, a key characteristic of a SAR long distance signal. Microscopic examination of leaf and petiole cross-sections demonstrated that DIR1-GUS expression was observed in all living cell types including developing xylem, xylem parenchyma, mesophyll, phloem parenchyma and phloem. Mature xylem tracheary elements are dead, and as expected appeared empty with no detectable GUS activity. DIR1 expression was reduced but still detectable after SAR induction in all living cell types including companion cells and phloem sieve elements. Therefore DIR1 is present at the right place (companion cells) and the right time (during SAR induction) to participate in long distance signaling during SAR.

The subcellular localization of DIR1 and the functionality of DIR1's predicted signal sequence were examined by transiently expressing DIR1-EYFP fusion proteins in tobacco epidermal cells followed by visualization using confocal microscopy. As expected, EYFP alone and a fusion construct lacking the predicted ER signal sequence (DIR ${ }^{\Delta 1-25}$-EYFP) localized to cytosolic strands and diffused into the nucleus while intact DIR1-EYFP localized to the ER, cell periphery and showed colocalization with propidium iodide, an apoplastic marker. DIR1-GUS activity was detected in intercellular washing fluids from plants expressing wild type DIR1, but GUS activity was greatly reduced in IWFs collected from plants expressing DIR1 lacking the signal sequence, corroborating the DIR1-EYFP tobacco localization experiments. Therefore, the DIR1 signal sequence does direct secretion of DIR1 to the cell wall as has been previously observed for other LTPs [37-39], Similar results were also obtained in a recent paper in which DIR-GFP transiently expressed in Nicotiana benthamiana was observed to localize to the ER [30]. It is difficult to distinguish the plasma membrane from the cell wall using light microscopy [38] and this may explain why Chanda et al. [30] concluded that DIR1 is not secreted to the cell wall. We chose to examine intercellular washing fluids for the presence of DIR1-GUS for two reasons: to overcome the light-microscopy-associated problem of distinguishing the plasma membrane from the cell wall and to demonstrate that DIR1 is secreted to the cell wall in both tobacco and Arabidopsis.

Evidence to date indicates that Arabidopsis proteins destined to travel in the phloem are synthesized in companion cells and move into sieve elements through plasmodesmata [50-52]. Patches of intracellular DIR1:EYFP were detected in this study, however it is difficult to distinguish the cytosol from the ER and the secretory system. Nevertheless, these data support the idea that some DIR1 protein is present in the cytosol and therefore gains access to the phloem through the cytosol of companion cells. Alternatively, DIR1 could enter the cytosol if the function of the signal sequence is disrupted during SAR induction. It is also possible that pathogen-induced cell membrane disruption during the HR (SAR induction) may allow cell wall proteins including DIR1 to enter cells. In any case, we hypothesized that cytosolic localization of a pool of DIR1 is required for translocation of the long-distance SAR signal. To address this question, a transgenic line was created in which the signal sequence was deleted from DIR1 (35S:DIR1 $1^{\Delta 1-25}$ GUS-5 in dir1-1 ). We chose to use the $35 \mathrm{~S}$ promoter in the signal sequence lines and the native DIR1 promoter in the DIR1pro:DIR1-GUS/dir1-1 lines because our data indicated that DIR1 expression was very low in wild type plants [21], and we wanted to increase the chance of observing DIR1-GUS in at least one of our lines. In retrospect, this was not necessary as DIR1 expression was observed in the DIR1pro:DIR1-GUS/ dir1-1 lines, however space and funding constraints made it necessary to work with the 35S: DIR1 $1^{\Delta 1-25}$ GUS-5/dir1-1 lines. Little DIR1 ${ }^{\Delta 1-25}$-GUS was detected in IWFs collected from 35S:DIR $1^{\Delta 1-25}$-GUS-5/dir1-1 plants. Additionally, removal of the signal sequence restricted expression of a DIR1-EYFP fusion to the cytosol in tobacco cells. Expression of DIR1 without its ER signal sequence rescued the SAR defect in dir1-1 to the same extent as the entire protein (DIR1pro:DIR1-GUS/ dir1-1). These experiments suggest that restricting DIR1 to the cytosol does not impair SAR and supports the idea that cytosolic localization of DIR1 is important during the induction stage of SAR. However, we can not rule out the possibility that higher levels of DIR1 ${ }^{\Delta 1-25}$ GUS produced from the $35 \mathrm{~S}$ promoter are responsible for the SAR competent phenotype observed in 35S: DIR1 ${ }^{\Delta 1-25}$-GUS-5/dir1-1 lines.

\section{Conclusions}

DIR1, like a number of other Arabidopsis LTPs, is expressed in seedlings, leaves, roots and flowers [72-74] and contains a signal sequence that directs it to the cell wall. Additionally, DIR1 is upregulated during the basal resistance response to Pst hrp mutants in a manner similarly observed in other plant-microbe systems [75]. Our results also confirm previous expression studies that LTPs in Arabidopsis are the targets of Hrp-dependent suppression by Pseudomonas syringae [31-33]. Although DIR1 expression is suppressed by Pst, DIR1 is still detected in companion cells during the SAR induction stage and restriction of DIR1 to the cytosol does not impair SAR, suggesting that DIR1 gains access to sieve elements for transport to distant leaves during SAR. In other words, DIR1 is perfectly situated to participate in long distance signaling during SAR. 


\section{Methods}

\section{Plant growth conditions}

Arabidopsis seeds from wild-type (ecotype Ws), dir1-1 and all transgenic Arabidopsis lines were surface sterilized, stratified for 2 days at $4{ }^{\circ} \mathrm{C}$ and germinated on solid Murashige and Skoog (MS) medium for 5 to 7 days under continuous light. Seedlings were transferred to soil (Sunshine Mix \#1), hydrated with $1 \mathrm{~g} / \mathrm{L} \mathrm{20-20-20}$ fertilizer and grown for 3-4 weeks at $22^{\circ} \mathrm{C}, 9 \mathrm{~h}$ photoperiod at $150 \mu \mathrm{E} \mathrm{m}^{-2} \mathrm{~s}^{-1}$ light intensity and $65-85 \%$ relative humidity.

\section{Pathogen culture and inoculation}

Virulent (containing pVSP1) and avirulent (containing pVSP1 + avrRpt2) Pseudomonas syringae pv. tomato DC3000 strains are previously described [65]. SAR experiments at McMaster were sometimes done using the coronatine mutant Pseudomonas syringae pv maculicola ES4326 (Psm) containing avrRpt2 strain [69]. No difference was found in terms of the ability to induce SAR. Bacteria were cultured overnight in King's B medium, diluted to either $10^{5}$ or $10^{6} \mathrm{cfu} \mathrm{ml}^{-1}$ in $10 \mathrm{mM}$ $\mathrm{MgCl}_{2}$ and pressure infiltrated into the abaxial side of a leaf using a $1 \mathrm{ml}$ syringe without needle. Quantification of in planta bacterial levels was performed by dilution plating essentially as described in [6].

\section{SAR assays}

Plant inoculations were initiated on 3.5 to 4 week old plants (24 to 28 days post germination, dpg). SAR was measured by comparing in planta growth of virulent bacteria in plants induced for SAR with Pst-avrRpt2 (SAR-induced) with growth in plants inoculated with 10 $\mathrm{mM} \mathrm{MgCl}_{2}$ (mock-inoculated). Plants were SARinduced by inoculation of two lower leaves with avirulent Pst $\left(10^{6} \mathrm{cfu} \mathrm{m}^{-1}\right)$ or mock-inoculated, followed by challenge inoculation of distant leaves with $10^{5} \mathrm{cfu} \mathrm{ml}^{-1}$ virulent Pst and in planta bacterial level determination 3 dpi. Bacterial density measurements were measured in triplicate for each genotype and treatment and were plotted as the mean \pm standard deviation. Pairwise statistical comparisons between SAR-induced plants and the mock-inoculated control were conducted using a Student's T-test at a 0.05 level of significance.

\section{Collection of intercellular washing fluids}

Fully expanded leaves of 3 to 4 week old Arabidopsis plants were vacuum infiltrated with sterile distilled water for $30 \mathrm{~min}$, blotted with absorbent paper to dry the leaf surfaces, followed by intercellular washing fluid (IWF) collection from leaves by centrifugation at $1000 \mathrm{~g}$ for $30 \mathrm{~min}$ at $4^{\circ} \mathrm{C}$ [76]. 50 leaves produced approximately 200-300 $\mu \mathrm{l}$ IWF, which is less than previously reported [77] likely because leaves from 3-4 week old plants are smaller than those from 5-7 week old plants. IWFs were sampled immediately for GUS activity.

\section{Subcellular localization}

Nicotiana tabaccum was grown under a 9 hour light cycle with $150 \mu \mathrm{E} \mathrm{m} \mathrm{m}^{-2} \mathrm{~s}^{-1}$ light intensity and ambient humidity. When plants were 5-6 weeks old, overnight cultures of Agrobacterium tumefaciens grown in LB medium were resuspended in freshly prepared infiltration buffer ( $50 \mathrm{mM}$ MES, $2 \mathrm{mM}$ sodium phosphate $\mathrm{pH}$ 5.6, $0.1 \mathrm{mM}$ acetosyringone, $13.4 \mathrm{mM}$ sucrose) at an $\mathrm{O}$. D. 600 of 0.1 then pressure infiltrated into the abaxial side of a nearly fully-expanded leaf using a $1 \mathrm{ml}$ syringe without needle. 48 hours later, leaf epidermal cells were imaged on a Zeiss Axiovert laser scanning confocal microscope. In some experiments, a $1 \mu \mathrm{g} / \mathrm{ml}$ solution of propidium iodide in water was pressure infiltrated as described 15 minutes before imaging. Using an argon laser, EYFP and propidium iodide were stimulated at $514 \mathrm{~nm}$ and $405 \mathrm{~nm}$ respectively, and detected with filter sets at 505-530 $\mathrm{nm}$ and 588-614 $\mathrm{nm}$.

\section{Preparation of tissue, GUS activity and light microscopy}

Harvested leaves were washed three times in $50 \mathrm{mM}$ sodium phosphate $\mathrm{pH} 7.0$ and vacuum infiltrated for 30 min with $\mathrm{X}$-glucuronide staining solution consisting of $1 \mathrm{mM} \mathrm{X}$-glucuronide (Rose Scientific, Edmonton), 0.02\% Silwet L-77, 20\% methanol (v/v), $10 \mathrm{mM}$ EDTA, $40 \mathrm{mM}$ sodium phosphate $\mathrm{pH} 7.0$ [78]. Staining was developed by overnight incubation at room temperature. Stained leaves were fixed for 24-72 h in a solution containing $3.7 \%$ formaldehyde in $50 \mathrm{mM}$ sodium phosphate $\mathrm{pH} 7.0$ then dehydrated and cleared by a graded ethanol series. Whole leaves were wet mounted in $70 \%$ ethanol and photographed with a Nikon DXM1200F digital camera mounted on a Leica Labrolux 12 microscope using either PHACO2 25/0.5 or Leitz Wetzlar EF 10/0.5 objective lenses. GUS activity or staining intensity was scored on a relative scale of 0 to 4 , with 0 representing no visible staining and 4 being extremely intense staining. Tissue to be embedded was excised from the stained and partially dehydrated leaf and further fixed for 2-24 h in a solution containing $1.85 \%$ formaldehyde, $5 \%$ glacial acetic acid and $63 \%$ ethanol by volume. Tissue was then completely dehydrated in a graded ethanol series and embedded in Spurr's resin (Marivac, Inc., Montreal). Spurr's resin blocks were sectioned into $1 \mu \mathrm{m}$ sections using a Reichert-Jung Ultracut ultramicrotome. Sections were fixed to a glass slide using heat and a portion of each slide was counterstained with an aqueous solution of $0.1 \%$ saffranin-o then destained in water. Slides were coverslipped in Permount ${ }^{\circledR}$ (Fisher Scientific, Hampton $\mathrm{NH}$ ) and photographed using a Zeiss 
AXIO imager D1 microscope fitted with EC PlanNEOFLUOR 10/0.3 and 100/1.3 objective lenses.

\section{Construction of DIR1-GUS transgenic lines}

A 1266-bp fragment corresponding to the DIR1 promoter region upstream of the initiation codon was PCR amplified, including engineered restriction sites, from Arabidopsis Ws genomic DNA using forward primer 5'CTTCTGCAGCATTATGGTGTTTTCCTTTG and reverse primer 5'-GTGGATCCTTGTGGTGTTGAAATGAATG. The engineered Pst I and BamHI restriction sites were then used to ligate the promoter fragment into the respective sites of pCAMBIA1391Z binary vector (Cambia, Australia) upstream of the GUS reporter gene, generating DIR1pro:GUS construct.

A 1613-bp fragment consisting of the native DIR1 promoter sequence immediately upstream of the start codon and DIR1 coding sequence minus stop codon was PCR amplified, including engineered restriction sites, from Ws genomic DNA using forward primer 5'CTTCTGCAGCATTATGGTGTTTCCTTTG and reverse primer 5'-AGTGAATTCACAAGTTGGGG CGTTG. The PCR product was digested with Pst $\& E c o R I$ and ligated in-frame upstream of the GUS gene of pCAMBIA1391Xa (Cambia), thus allowing translational fusion of DIR1/LTP to GUS and the resulting vector construct was designated as DIR1pro:DIR1:GUS.

A 397-bp fragment consisting of a truncated DIR lacking signal sequence DIR1 ${ }^{\Delta 1-25}$, and having an engineered ATG, native stop codon, plus entire 3' UTR was PCR amplified from Ws genomic DNA using forward primer 5'-ATGGCGATAGATCTCTGCGGC and reverse primer 5'-TGTTtgGgCCTTGTGTAGTTTTC. The blunt-end PCR fragment was ligated into the SmaI site of pBI121 and its sequence was analyzed to be in correct orientation. The recombinant plasmid was digested with PstI and EcoRI to release a 3.4-kb fragment, including CaMV35S promoter, and ligated into the PstI/EcoRI sites of pCAMBIA1391Z, resulting in the vector construct designated as 35S: DIR $1^{\Delta 1-25}$.

A 1114-bp fragment consisting of $35 \mathrm{~S}$ promoter and a truncated DIR1 $1^{\Delta 1-25}$ was PCR amplified from the pMNDIR1-ssT15 vector (a recombinant pBI121 harbouring the DIR1 gene) using forward primer 5'-AGCGGATAACAATTTCACACAGG and reverse primer 5'AGTGAATTCACAAGTTGGGGCGTTG. The PCR product was digested with HindIII and EcoRI and cloned in-frame to the GUS gene of pCAMBIA1391Xa, resulting in the construct 35S: DIR1 $1^{\Delta 1-25}$-GUS.

Each plasmid was sequenced prior to transferring it into Agrobacterium tumefaciens GV3101 via electroporation. Each of these constructs was introduced into dir1-1 mutant plants except for the DIR1 promoterGUS fusion construct which was introduced into wild- type Ws plants via the Agrobacterium mediated floral dip transformation technique [79].

\section{Characterization of DIR1-GUS transgenic lines}

Putative primary independent transformants for each construct were selected in the $\mathrm{T} 1$ generation by plating $\sim 1800$ seeds (T1) on MS medium containing $15 \mathrm{mg} / \mathrm{l}$ hygromycin, with a germination frequency of $1.2-1.6 \%$. After selection for 8-10 days, surviving hygromycinresistant $\mathrm{T} 1$ seedlings were transplanted into soil and checked for the presence of the transgene by PCR using GUS primers 32 GUS $^{+}$(5'-GTCTGGTATCAGCGCGAAGT-3') and 33 GUS $^{-}$(5'-GGCACAGCACATCAAAGAGA-3'). Hygromycin-resistant and GUScontaining seedlings were allowed to self-fertilize in order to obtain T2 seed. At least 5 - 10 independent transformants for each of the four constructs were screened for homozygous transgenic plants in the T2 generation based on segregation of the selectable marker gene. Approximately $80 \mathrm{~T} 2$ seeds derived from each independent $\mathrm{T} 1$ mother plant $\left(\mathrm{Hyg}^{+}, \mathrm{GUS}^{+}\right)$were grown on hygromycin-containing MS medium and lines which showed $100 \%$ survival were considered homozygous. At least 10-15 $\mathrm{T} 2$ seedlings from the same $\mathrm{T} 1$ parents were screened for the presence of the transgene using PCR and primers that were specific for each construct, i.e. GUS primers for the DIRpro:DIR1-GUS, 35Spro: DIR1 ${ }^{\Delta 1-25}$-GUS, and DIR1pro:GUS transgenics, and DIR1 specific primers LTP-SSF1 (5'-ATGGCGATAGATCTCTGCGGC-3') and LTP-SSR4 (5'-TGTTT GGGCCTTGTGTAGTTTTC-3') for the 35Spro:DIR1SS transgenic.

Histochemical assays of ß-glucuronidase (GUS) activity [78] were also performed on leaf samples from 3 to 5 T2 plants derived from at least 4 independently-transformed homozygous DIR1pro:GUS in Ws lines (L1, 4, 11, 23), DIR1pro:DIR1-GUS in dir1-1 lines (L1, 3, 4, 15, $14,17,29)$ and 35Spro: DIR1 ${ }^{\Delta 1-25}$-GUS in dir1-1 lines (L1, 5, 7, 9, 17). DIR1pro:GUS in Ws lines $(1,11,23)$, DIR1pro:DIR1-GUS in dir1-1 lines $(1,3,29)$ and 35Spro: DIR1-ss-GUS in dir1-1 lines $(1,5,7)$ displayed a similar intense uniform staining pattern and were determined to be homozygous as described above and were used in subsequent experiments.

\section{Construction of Agrobacterium expressing EYFP fusion proteins}

Binary transformation vectors expressing C-terminal EYFP fusion proteins under the control of the $35 \mathrm{~S}$ promoter were generated using Gateway ${ }^{\circledR}$ technology from Invitrogen. Sequence encompassing full-length DIR1 but lacking a stop codon was PCR amplified from Arabidopsis Ws genomic DNA using forward primer 5'-GGGGACAAGTTTGTACAAAAAAGCAGGCTTAATGGCGAG 
CAAGAAAGCAGCT and reverse primer 5'-GGGGACCACTTTGTACAAGAAAGCTGGGTTACAAGTTG GGGCGTTGGC DIR1 lacking its secretion signal sequence but including an engineered start codon was PCR amplified with forward primer 5'-GGGGACAAGTTTGTACAAAAAAGCAGGCTTAATGGCGATAGATCTCTGCGG and the reverse primer described above. EYFP was PCR amplified from pEYFP-N1 (Clontech) with forward primer 5'-GGGGACAAGTTTGTACAAAAAAGCAGGCTTAATGGTGAGCAAGGGCGAGGA and reverse primer 5'-GGGGACCACTTTG TACAAGAAAGCTGGGTTACTTGTACAGCTCGTC CATGCC. PCR products were recombined into entry vector pDONR221 using a BP recombination reaction according to the manufacturer's instructions. LR recombination reactions were performed according to the manufacturer's instructions to introduce these coding sequences into plant binary transformation vector p35S-NEYFP, which is based on pMDC83 [80]. Resulting plasmids 35S:DIR1EYFP, 35S: DIR1 ${ }^{\Delta 1-25}$-EYFP and 35S:EYFP were sequenced, mobilized into Agrobacterium tumefaciens strain GV3101/PmP90 by electroporation and transformed bacteria were selected on $2 \mathrm{YT}$ medium containing rifampicin, gentamycin and spectinomycin.

\section{RNA gel blot analysis}

Total RNA was isolated from Arabidopsis leaves using the RNAgents total RNA isolation system (Promega). The RNA concentration was determined by absorbance at $260 \mathrm{~nm}$, and then separated on $2 \%$ formaldehyde denaturing agarose gels. The RNA was transferred onto Hybond $\mathrm{N}+$ nylon membranes (Amersham, Piscataway, NJ, USA) using 10X SSC, and UV-crosslinked using a Stratalinker (Stratagene, La Jolla, CA, USA) with the auto-crosslink setting. The DIR1 gene was amplified from Col-0 genomic DNA using the following primers: DIR1For 5'-AGCAATCCAATCTGGTTCAC-3' and DIR1Rev 5'-TAACATCCGATATTTAGAATAGGAG-3'. The 491bp DIR1 fragment was cloned, reamplified using vector primers and labeled with ${ }^{32} \mathrm{P}$-dCTP using the Stratagene Prime-It II random primer labeling kit. RNA blot hybridization with the DIR1 probe was performed using PerfectHyb Plus hybridization buffer (Sigma, St. Louis, MO, USA) following the manufacturer's protocol, and then washed with $0.5 \times$ SSC and exposed to film.

\section{Additional material}

Additional file 1: Supplementary Figure S1. GUS expression in DIR1pro:GUS-23 leaves. DIR1pro:GUS-23 was left untreated, mock

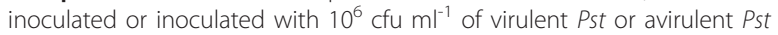
avrRpt2 and harvested for histochemical GUS analysis at $20 \mathrm{hpi}$. Untreated, mock inoculated, inoculated and systemic leaves were processed and photographed as in Figure 1.
Additional file 2: Supplementary Figure S2. DIR1-GUS expression in DIR1pro:DIR1-GUS-3/dir1-1 leaves. DIR1pro:DIR1-GUS-3 in dir1-1 was. left untreated, mock inoculated or inoculated with $10^{6} \mathrm{cfu} \mathrm{ml}^{-1}$ of virulent Pst or avirulent Pst avrRpt2 and harvested for histochemical GUS analysis at $14 \mathrm{hpi}$. Untreated, mock inoculated, inoculated and systemic leaves were processed and photographed as in Figure 1.

Additional file 3: Supplementary Figure S3. Relative GUS activity in DIR1pro:DIR1-GUS and DIR1pro:GUS lines. Untreated, mock inoculated, inoculated and systemic leaves from SAR-induced plants in experiments presented in Figure 1 and Supplementary Figures 1 and 2 were scored using the scale described in Figure 1B. Asterisks denote a significant difference between treatment and mock control.

Additional File 4: Supplementary Figure S4. GUS expression in DIR1pro:GUS-11/dir1-1 and DIR1pro:DIR1-GUS-29/dir1-1 vasculature. 3.5 week-old DIR1pro:GUS-11/dir1-1 was mock inoculated and DIR1 pro: DIR1-GUS-29/dir1-1 was inoculated with $10^{6} \mathrm{cfu} \mathrm{ml}^{-1}$ avirulent Pst avrRpt2. Leaves were sampled $20 \mathrm{hpi}$ and sectioned through the midvein. Abbreviations: SE - sieve tube element; CC - companion cell (additional SE/CC pairs are circled); $X i$ - immature xylem vessel; $X m$ - mature xylem vessel; Xp - Xylem parenchyma.

Additional file 5: Supplementary Figure S5. Localization of DIR1 at various developmental stages in DIR1 promoter- GUS lines. Various tissues were stained for GUS and photographed. A. Ws seedling $7 \mathrm{dpg}$ B. DIR1 pro:DIR1-GUS-29/dir1-1 seedling 7 dpg C. 35S:DIR1 ${ }^{\Delta 1-25}$-GUS-5/dir1-1 seedling 7 dpg D. DIR1pro:DIR1-GUS-29/dir7-1 flower and E. flower bolt F. DIR1pro:DIR1-GUS-29/dir1-1 seedling roots and G. root hairs H. Crosssection of DIR1 pro:DIR1-GUS-29/dir7-1 untreated petiole. I. Cross-section of 35S: DIR1 ${ }^{\Delta 1-25}$-GUS-5/dir 1-1 untreated petiole.

Additional file 6: Supplementary Figure S6. GUS expression in 35S: DIR1 ${ }^{\Delta 1-25}$-GUS-17/dir1-1 leaves. 35S:DIR1 ${ }^{\Delta 1-25}$-GUS-17/dir1-1 was left untreated, mock inoculated or inoculated with $10^{6} \mathrm{cfu} \mathrm{ml}^{-1}$ of avirulent Pst avrRpt2 and harvested for histochemical GUS analysis at $20 \mathrm{hpi}$. Midveins and mesophyll cells of untreated, mock inoculated, inoculated and systemic leaves were processed and photographed. Relative GUS staining was scored according to the scale in Figure 1B.

\section{Acknowledgements and Funding}

We thank Yangdou Wei (University of Saskatchewan) for assistance with confocal microscopy. This work was supported by grants to R. Cameron (Natural Science and Engineering Research Council of Canada Discovery Grant, Premier's Research Excellence Award of Ontario) and Start-up funding and growth chamber maintenance support from McMaster University as well as an NSERC Discovery grant to P. Fobert and a U. S. Department of Energy and National Science Foundation grant to S.Y. He.

\section{Author details}

'Department of Biology, McMaster University, Hamilton, ON L8S 4K1 Canada. ${ }^{2}$ Department of Cell and Systems Biology, University of Toronto, 25 Willcocks Street, Toronto, ON, M5S 3B2, Canada. ${ }^{3}$ Department of Plant Biology,

Michigan State University, East Lansing MI, 48824 USA. ${ }^{4}$ Plant Biotechnology Institute, 110 Gymnasium Place, Saskatoon, SK S7N OW9 Canada. ${ }^{5}$ USDA-ARS, Western Regional Research Center, Crop Improvement and Utilization Research Unit, 800 Buchanan St., Albany, CA, 94710 USA.

\section{Authors' contributions}

$\mathrm{RC}$ conceived of most of the experiments and she and her lab members performed the majority of the experiments presented: MN created the transgenic DIR1-GUS and DIR1 ${ }^{\Delta 1-25}$-GUS Arabidopsis lines, AM and KH molecularly characterized these lines, HS performed microscopy, including quantifying relative GUS intensity of these lines. MC contributed significantly to writing the manuscript, conceived of and subcellularly localized DIR1 in tobacco epidermal cells, performed disease resistance assays and constructed the Agrobacterium 35S:DIR1-EYFP, DIR1 ${ }^{\Delta 1-25}$-EYFP and EYFP lines. PF supported MC's tobacco work. RT and SH performed the RNA gel blots of DIR1 expression in response to hrpPst. ND provided plant cell biology expertise. All authors read and approved the final manuscript. 
Received: 10 June 2011 Accepted: 6 September 2011

Published: 6 September 2011

\section{References}

1. Chester KS: The problem of acquired physiological immunity in plants. Quart Rev Biol 1933, 8:275-324.

2. Ross AF: Systemic acquired resistance induced by localized virus infections in plants. Virology 1961, 14:340-358.

3. Kuc J: Induced immunity to plant disease. Bioscience 1982, 32:854-856.

4. Ross AF: Systemic effects of local lesion formation. In Viruses of plants. Edited by: Beemster ABR, Dijkstra J. Amsterdam: North-Holland Publ. Comp.; 1966:127-150

5. Mishina TE, Zeier J: Pathogen-associated molecular pattern recognition rather than development of tissue necrosis contributes to bacterial induction of systemic acquired resistance in Arabidopsis. Plant J 2007, 50(3):500-513.

6. Cameron RK, Paiva NL, Lamb CJ, Dixon RA: Accumulation of salicylic acid and PR-1 gene transcripts in relation to the systemic acquired resistance (SAR) response induced by Pseudomonas syringae pv. tomato in Arabidopsis. Physiol Mol Plant P 1999, 55(2):121-130.

7. Delaney TP, Friedrich L, Ryals JA: Arabidopsis signal transduction mutant defective in chemically and biologically induced disease resistance. Proc Natl Acad Sci USA 1995, 92(14):6602-6606.

8. Lawton K, Weymann K, Friedrich L, Vernooij B, Uknes S, Ryals J: Systemic acquired resistance in Arabidopsis requires salicylic acid but not ethylene. Mol Plant Microbe In 1995, 8(6):863-870.

9. Malamy J, Klessig DF: Salicylic Acid and Plant Disease Resistance. Plant J 1992, 2(5):643-654

10. Metraux JP, Signer H, Ryals J, Ward E, Wyss-Benz M, Gaudin J, Raschdorf K, Schmid E, Blum W, Inverardi B: Increase in salicylic Acid at the onset of systemic acquired resistance in cucumber. Science 1990, 250(4983):1004-1006.

11. Yalpani N, Silverman P, Wilson TM, Kleier DA, Raskin I: Salicylic acid is a systemic signal and an inducer of pathogenesis-related proteins in virusinfected tobacco. Plant Cell 1991, 3(8):809-818.

12. Uknes $S$, Dincher $S$, Friedrich $L$, Negrotto $D$, Williams $S$, Thompsontaylor $H$, Potter S, Ward E, Ryals J: Regulation of Pathogenesis-Related Protein-1a Gene Expression in Tobacco. Plant Cell 1993, 5(2):159-169.

13. Champigny MJ, Cameron RK: Action at a Distance: Long-Distance Signals in Induced Resistance. Plant Innate Immunity 2009, 51:123-171.

14. Gaffney T, Friedrich L, Vernooij B, Negrotto D, Nye G, Uknes S, Ward E, Kessmann H, Ryals J: Requirement of Salicylic Acid for the Induction of Systemic Acquired-Resistance. Science 1993, 261(5122):754-756.

15. Rasmussen JB, Hammerschmidt R, Zook MN: Systemic induction of salicylic acid accumulation in cucumber after inoculation with Pseudomonas syringae pv syringae. Plant Physiol 1991, 97:1342-1347.

16. Vernooij B, Friedrich L, Morse A, Reist R, Kolditzjawhar R, Ward E, Uknes S, Kessmann H, Ryals J: Salicylic Acid Is Not the Translocated Signal Responsible for Inducing Systemic Acquired Resistance but Is Required in Signal Transduction. Plant Cell 1994, 6(7):959-965.

17. Ward ER, Uknes SJ, Williams SC, Dincher SS, Wiederhold DL, Alexander DC, Ahlgoy P, Metraux JP, Ryals JA: Coordinate Gene Activity in Response to Agents That Induce Systemic Acquired Resistance. Plant Cell 1991, 3(10):1085-1094

18. Smith JA, Hammerschmidt R, Fullbright DW: Rapid induction of systemic resistance in cucumber by Pseudomonas sysringae pv syringae. Physiol Mol Plant P 1991, 33:255-261.

19. Siegrist J, Jeblick W, Kauss H: Defense Responses in Infected and Elicited Cucumber (Cucumis sativus L) Hypocotyl Segments Exhibiting Acquired Resistance. Plant Physiol 1994, 105(4):1365-1374.

20. Van Loon LC, Van Strien EA: The families of pathogenesis-related proteins, their activities, and comparative analysis of PR-1 type proteins. Physiol Mol Plant P 1999, 55(2):85-97.

21. Maldonado AM, Doerner P, Dixon RA, Lamb CJ, Cameron RK: A putative lipid transfer protein involved in systemic resistance signalling in Arabidopsis. Nature 2002, 419(6905):399-403.

22. Yeats TH, Rose JKC: The biochemistry and biology of extracellular plant lipid-transfer proteins (LTPs). Protein Sci 2008, 17(2):191-198.

23. Lascombe MB, Bakan B, Buhot N, Marion D, Blein JP, Larue V, Lamb C, Prange T: The structure of "defective in induced resistance" protein of
Arabidopsis thaliana, DIR1, reveals a new type of lipid transfer protein. Protein Sci 2008, 17(9):1522-1530.

24. Nandi A, Welti R, Shah J: The Arabidopsis thaliana dihydroxyacetone phosphate reductase gene SUPPRESSOR OF FATTY ACID DESATURASE $D E F I C I E N C Y 1$ is required for glycerolipid metabolism and for the activation of systemic acquired resistance. Plant Cell 2004, 16(2):465-477.

25. Chaturvedi R, Krothapalli K, Makandar R, Nandi A, Sparks AA, Roth MR, Welti R, Shah J: Plastid omega 3-fatty acid desaturase-dependent accumulation of a systemic acquired resistance inducing activity in petiole exudates of Arabidopsis thaliana is independent of jasmonic acid. Plant J 2008, 54(1):106-117.

26. Park SW, Kaimoyo E, Kumar D, Mosher S, Klessig DF: Methyl salicylate is a critical mobile signal for plant systemic acquired resistance. Science 2007, 318(5847):113-116

27. Vlot AC, Liu PP, Cameron RK, Park SW, Yang Y, Kumar D, Zhou F, Padukkavidana T, Gustafsson C, Pichersky E, Klessig DF: Identification of likely orthologs of tobacco salicylic acid-binding protein 2 and their role in systemic acquired resistance in Arabidopsis thaliana. Plant J 2008, 56(3):445-456

28. Jung HW, Tschaplinski TJ, Wang L, Glazebrook J, Greenberg JT: Priming in Systemic Plant Immunity. Science 2009, 324(5923):89-91.

29. Liu PP, von Dahl CC, Park SW, Klessig DF: Interconnection between Methyl Salicylate and Lipid-Based Long-Distance Signaling during the Development of Systemic Acquired Resistance in Arabidopsis and Tobacco. Plant Physiol 2011, 155(4):1762-1768.

30. Chanda B, Xia Y, Mandal MK, Yu K, Sekine KT, Gao QM, Selote D, Hu Y, Stromberg A, Navarre D, Kachroo A, Kachroo P: Glycerol-3-phosphate is a critical mobile inducer of systemic immunity in plants. Nat Genet 2011.

31. Underwood W, Zhang SQ, He SY: The Pseudomonas syringae type III effector tyrosine phosphatase HopAO1 suppresses innate immunity in Arabidopsis thaliana. Plant J 2007, 52(4):658-672.

32. Hauck P, Thilmony R, He SY: A Pseudomonas syringae type III effector suppresses cell wall-based extracellular defense in susceptible Arabidopsis plants. P Natl Acad Sci USA 2003, 100(14):8577-8582.

33. Chen ZY, Kloek AP, Boch J, Katagiri F, Kunkel BN: The Pseudomonas syringae avrRpt2 gene product promotes pathogen virulence from inside plant cells. Mol Plant Microbe In 2000, 13(12):1312-1321.

34. Thilmony R, Underwood W, He SY: Genome-wide transcriptional analysis of the Arabidopsis thaliana interaction with the plant pathogen Pseudomonas syringae pv. tomato DC3000 and the human pathogen Escherichia coli 0157 : H7. Plant J 2006, 46(1):34-53.

35. Hutcheson SW, Bretz J, Sussan T, Jin SM, Pak K: Enhancer-binding proteins HrpR and HrpS interact to regulate hrp-encoded type III protein secretion in Pseudomonas syringae strains. J Bacteriol 2001, 183(19):5589-5598.

36. Wei WS, Plovanich-Jones A, Deng WL, Jin QL, Collmer A, Huang HC, He SY: The gene coding for the Hrp pilus structural protein is required for type III secretion of Hrp and Avr proteins in Pseudomonas syringae pv. tomato. P Natl Acad Sci USA 2000, 97(5):2247-2252.

37. Thoma S, Kaneko Y, Somerville C: A Nonspecific Lipid Transfer Protein from Arabidopsis Is a Cell Wall Protein. Plant J 1993, 3(3):427-436.

38. Pyee J, Yu HS, Kolattukudy PE: Identification of a Lipid Transfer Protein as the Major Protein in the Surface Wax of Broccoli (Brassica oleracea) Leaves. Arch Biochem Biophys 1994, 311(2):460-468.

39. Kader JC: Lipid-transfer proteins in plants. Annu Rev Plant Phys 1996, 47:627-654.

40. Carvalho AD, Teodoro CED, Da Cunha M, Okorokova-Facanha AL, Okorokov LA, Fernandes KVS, Gomes VM: Intracellular localization of a lipid transfer protein in Vigna unguiculata seeds. Physiol Plantarum 2004, 122(3):328-336.

41. Yamada M: Lipid Transfer Proteins in Plants and Microorganisms. Plant Cell Physiol 1992, 33(1):1-6.

42. Nigg EA: Nucleocytoplasmic transport: Signals, mechanisms and regulation. Nature 1997, 386(6627):779-787.

43. Berg RH, Beachy RN: Fluorescent protein applications in plants. Method Cell Biol 2008, 85:153-+.

44. Amano $Y$, Tsubouchi $H$, Shinohara H, Ogawa M, Matsubayashi Y: Tyrosinesulfated glycopeptide involved in cellular proliferation and expansion in Arabidopsis. P Natl Acad Sci USA 2007, 104(46):18333-18338. 
45. Takano J, Noguchi K, Yasumori M, Kobayashi M, Gajdos Z, Miwa K, Hayashi H, Yoneyama T, Fujiwara T: Arabidopsis boron transporter for xylem loading. Nature 2002, 420(6913):337-340.

46. Malnoy M, Venisse JS, Reynoird JP, Chevreau E: Activation of three pathogen-inducible promoters of tobacco in transgenic pear (Pyrus communis L.) after abiotic and biotic elicitation. Planta 2003, 216(5):802-814.

47. Goddijn OJM, Lindsey K, Vanderlee FM, Klap JC, Sijmons PC: Differential Gene Expression in Nematode Induced Feeding Structures of Transgenic Plants Harboring Promoter Gus-a Fusion Constructs. Plant J 1993, 4(5):863-873.

48. Flury T, Wagner $\mathrm{E}$, Kreuz K: An inducible glutathione S-transferase in soybean hypocotyl is localized in the apoplast. Plant Physiol 1996, 112(3):1185-1190

49. Kristensen AK, Brunstedt J, Nielsen KK, Roepstorff P, Mikkelsen JD: Characterization of a new antifungal non-specific lipid transfer protein (nsLTP) from sugar beet leaves. Plant Sci 2000, 155(1):31-40.

50. Haritatos $E$, Medville $R$, Turgeon R: Minor vein structure and sugar transport in Arabidopsis thaliana. Planta 2000, 211(1):105-111.

51. Imlau A, Truernit E, Sauer N: Cell-to-cell and long-distance trafficking of the green fluorescent protein in the phloem and symplastic unloading of the protein into sink tissues. Plant Cell 1999, 11(3):309-322.

52. Stadler R, Wright KM, Lauterbach C, Amon G, Gahrtz M, Feuerstein A, Oparka KJ, Sauer N: Expression of GFP-fusions in Arabidopsis companion cells reveals non-specific protein trafficking into sieve elements and identifies a novel post-phloem domain in roots. Plant $J$ 2005, 41(2):319-331.

53. Buhot N, Gomes E, Milat ML, Ponchet M, Marion D, Lequeu J, Delrot S, Coutos-Thevenot P, Blein JP: Modulation of the biological activity of a tobacco LTP1 by lipid complexation. Mol Biol Cell 2004, 15(11):5047-5052.

54. Douliez JP, Michon T, Marion D: Steady-state tyrosine fluorescence to study the lipid-binding properties of a wheat non-specific lipid-transfer protein (nsLTP1). Bba-Biomembranes 2000, 1467(1):65-72.

55. Douliez JP, Jegou S, Pato C, Molle D, Tran V, Marion D: Binding of two mono-acylated lipid monomers by the barley lipid transfer protein, LTP1, as viewed by fluorescence, isothermal titration calorimetry and molecular modelling. Eur J Biochem 2001, 268(2):384-388.

56. Kader JC: Lipid-transfer proteins: A puzzling family of plant proteins. Trends Plant Sci 1997, 2(2):66-70.

57. Tassin S, Broekaert WF, Marion D, Acland DP, Ptak M, Vovelle F, Sodano P. Solution structure of Ace-AMP1, a potent antimicrobial protein extracted from onion seeds. Structural analogies with plant nonspecific lipid transfer proteins. Biochemistry-Us 1998, 37(11):3623-3637.

58. Tassin-Moindrot S, Caille A, Douliez JP, Marion D, Vovelle F: The wide binding properties of a wheat nonspecific lipid transfer protein. Solution structure of a complex with prostaglandin B2. Eur J Biochem 2000, 267(4):1117-1124.

59. Kader JC, Julienne M, Vergnolle C: Purification and characterization of a spinach leaf protein capable of transferring phospholipids from liposomes to mitochondria or chloroplasts. Eur J Biochem 1984, 139(2):411-416.

60. Terras FRG, Goderis IJ, Vanleuven F, Vanderleyden J, Cammue BPA, Broekaert WF: In vitro Antifungal Activity of a Radish (Raphanus sativus L) Seed Protein Homologous to Nonspecific Lipid Transfer Proteins. Plant Physiol 1992, 100(2):1055-1058.

61. Cammue BP, Thevissen K, Hendriks M, Eggermont K, Goderis IJ, Proost P, Van Damme J, Osborn RW, Guerbette F, Kader JC, et al: A potent antimicrobial protein from onion seeds showing sequence homology to plant lipid transfer proteins. Plant Physiol 1995, 109(2):445-455.

62. Molina A, GarciaOlmedo F: Enhanced tolerance to bacterial pathogens caused by the transgenic expression of barley lipid transfer protein LTP2. Plant J 1997, 12(3):669-675.

63. Jayaraj J, Punja ZK: Combined expression of chitinase and lipid transfer protein genes in transgenic carrot plants enhances resistance to foliar fungal pathogens. Plant Cell Rep 2007, 26(9):1539-1546.

64. Dong X, Mindrinos M, Davis KR, Ausubel FM: Induction of Arabidopsis defense genes by virulent and avirulent Pseudomonas syringae strains and by a cloned avirulence gene. Plant Cell 1991, 3(1):61-72.

65. Whalen MC, Innes RW, Bent AF, Staskawicz BJ: Identification of Pseudomonas syringae pathogens of Arabidopsis and a bacterial locus determining avirulence on both Arabidopsis and soybean. Plant Cell 1991, 3(1):49-59.

66. Guttman DS, Greenberg JT: Functional analysis of the type III effectors AvrRpt2 and AvrRpm1 of Pseudomonas syringae with the use of a singlecopy genomic integration system. Mol Plant Microbe In 2001, 14(2):145-155.

67. Cameron RK, Dixon RA, Lamb CJ: Biologically Induced Systemic Acquired Resistance in Arabidopsis thaliana. Plant J 1994, 5(5):715-725.

68. Varet A, Hause B, Hause G, Scheel D, Lee J: The Arabidopsis NHL3 gene encodes a plasma membrane protein and its overexpression correlates with increased resistance to Pseudomonas syringae pv. tomato DC3000. Plant Physiol 2003, 132(4):2023-2033.

69. Cui J, Bahrami AK, Pringle EG, Hernandez-Guzman G, Bender CL, Pierce NE, Ausubel FM: Pseudomonas syringae manipulates systemic plant defenses against pathogens and herbivores. P Natl Acad Sci USA 2005, 102(5):1791-1796.

70. Zabala MD, Bennett MH, Truman WH, Grant MR: Antagonism between salicylic and abscisic acid reflects early host-pathogen conflict and moulds plant defence responses. Plant J 2009, 59(3):375-386.

71. Thines B, Katsir L, Melotto M, Niu Y, Mandaokar A, Liu GH, Nomura K, He SY, Howe GA, Browse J: JAZ repressor proteins are targets of the SCFCO11 complex during jasmonate signalling. Nature 2007, 448(7154):661-U662.

72. Thoma S, Hecht U, Kippers A, Botella J, Devries S, Somerville C: TissueSpecific Expression of a Gene Encoding a Cell Wall-Localized Lipid Transfer Protein from Arabidopsis. Plant Physiol 1994, 105(1):35-45.

73. Clark AM, Bohnert HJ: Cell-specific expression of genes of the lipid transfer protein family from Arabidopsis thaliana. Plant Cell Physiol 1999, 40(1):69-76.

74. Arondel V, Vergnolle C, Cantrel C, Kader JC: Lipid transfer proteins are encoded by a small multigene family in Arabidopsis thaliana. Plant Sci 2000, 157(1):1-12.

75. Garcia-Olmedo F, Molina A, Segura A, Moreno M: The defensive role of nonspecific lipid-transfer proteins in plants. Trends Microbiol 1995, 3(2):72-74.

76. Kus JV, Zaton K, Sarkar R, Cameron RK: Age-related resistance in Arabidopsis is a developmentally regulated defense response to Pseudomonas syringae. Plant Cell 2002, 14(2):479-490.

77. Cameron RK, Zaton K: Intercellular salicylic acid accumulation is important for age-related resistance in Arabidopsis to Pseudomonas syringae. Physiol Mol Plant P 2004, 65(4):197-209.

78. Jefferson RA, Kavanagh TA, Bevan MW: Beta-Glucuronidase (Gus) as a Sensitive and Versatile Gene Fusion Marker in Plants. J Cell Biochem 1987, 57-57.

79. Clough SJ, Bent AF: Floral dip: a simplified method for Agrobacteriummediated transformation of Arabidopsis thaliana. Plant J 1998 16(6):735-743

80. Curtis MD, Grossniklaus U: A gateway cloning vector set for highthroughput functional analysis of genes in planta. Plant Physiol 2003, 133(2):462-469.

doi:10.1186/1471-2229-11-125

Cite this article as: Champigny et al.: Localization of DIR1 at the tissue, cellular and subcellular levels during Systemic Acquired Resistance in Arabidopsis using DIR1:GUS and DIR1:EGFP reporters. BMC Plant Biology 2011 11:125.

\section{Submit your next manuscript to BioMed Central and take full advantage of:}

- Convenient online submission

- Thorough peer review

- No space constraints or color figure charges

- Immediate publication on acceptance

- Inclusion in PubMed, CAS, Scopus and Google Scholar

- Research which is freely available for redistribution

Submit your manuscript at www.biomedcentral.com/submit
C Biomed Central 